\title{
Sinonasal Anatomic Variations According to Frontal Sinus Pneumatization in a Korean Population
}

\author{
Myeongsin Kang, Jung-Hun Kown ${ }^{1}$, Dong-Hyun Kim ${ }^{1}$, Seung-Yoon Han ${ }^{1}$, and Jae-Hoon Lee ${ }^{1,2}$ (D) \\ ${ }^{I}$ Department of Otolaryngology, Wonkwang University School of Medicine, Iksan; and \\ ${ }^{2}$ Institute of Wonkwang Medical Science, Wonkwang University School of Medicine, Iksan, Korea \\ 한국인에서 전두동 함기화에 따른 비부비동의 해부학적 변화 \\ 강명신 $^{1} \cdot$ 권정훈 $^{1} \cdot$ 김동현 $^{1} \cdot$ 한승윤 $^{1} \cdot$ 이재훈 ${ }^{1,2}$ \\ 원광대학교 의과대학 이비인후과학교실, ${ }^{1}$ 원광대학교 의과대학 의과학연구소 ${ }^{2}$
}

Received September 4, 2020

Revised November 5, 2020

Accepted November 12, 2020

Address for correspondence

Jae-Hoon Lee, MD

Department of Otolaryngology,

Wonkwang University

School of Medicine,

18 Gobong-ro 24-gil,

Iksan 54538, Korea

Tel $+82-63-859-1441$

Fax $+82-63-841-6556$

E-mailLeejaehoon64@gmail.com
Background and Objectives It is necessary to understand the variations of the paranasal sinuses (PNS) and other anatomical structures during an endoscopic sinus surgery (ESS). The purpose of this study was to investigate any association between the degree of frontal sinus (FS) pneumatization and the development of the PNS structures.

Subjects and Method We analyzed 311 PNS computed tomography (CT) scans (622 sinuses, including the left and right sides). We classified FS into type I (aplasia), type II (hypoplasia), and type III (control). We assessed and compared the middle turbinate pneumatization (MTP), superior turbinate pneumatization (STP), agger nasi cell (ANC), infraorbital cell (IOC), optic nerve (ON) type, and vidian nerve (VN) type with the pneumatization of the FS. We further studied for any association between the degree of pneumatization of the FS, maxillary sinus (MS), and sphenoid sinus (SS) and the lateral lamella length (LLL).

Results MTP, ANC, and IOC rates according to the FS types were not significant $(p>0.05)$. Both type II and III showed more frequent occurrences of STP than type I ( $p=0.005)$. The ON type III and IV were significantly frequent in the FS type III $(p<0.001)$. The occurrence of VN type III in the FS type I was significant $(p<0.001)$. When comparing the pneumatizations of FS with MS or SS, there were no significant correlations between them $(p>0.05)$. In the FS type II and III, the LLL was significantly greater than in type I $(p<0.001)$.

Conclusion Increased FS pneumatization shows greater indentation of $\mathrm{ON}$ and $\mathrm{VN}$ into the SS, as well as increased LLL. During ESS, it is important to recognize the possibility of structural damage of ON, VN, and LLL according to FS pneumatization.

Korean J Otorhinolaryngol-Head Neck Surg 2021;64(7):473-8

Key Words Anatomical variation · Frontal sinus · Lateral lamella Optic nerve

Vidian nerve.

\section{Introduction}

Endoscopic sinus surgery (ESS) is a common surgical treatment for chronic sinusitis. Although the navigation system re-

This is an Open Access article distributed under the terms of the Creative Commons Attribution Non-Commercial License (https://creativecommons.org/licenses/by-nc/4.0) which permits unrestricted non-commercial use, distribution, and reproduction in any medium, provided the original work is properly cited. duces the risks in an endoscopic surgery, the wide anatomical diversity limits the application of endoscopy. Therefore, it is essential to understand the developmental state and variations of the paranasal sinuses (PNSs) and the other anatomical structures. The developmental state of the frontal sinus (FS) can be classified into aplasia, hypoplasia, and control groups. There is limited literature between the relation of the degree of FS 
pneumatization and the development of the PNS structures. ${ }^{1-4)}$

Lateral lamella length (LLL) and olfactory fossa depth are important anatomical parameters to be considered in preventing surgical complications like skull base injury. Greater LLL increases the possibility of lateral lamella injury during the surgery. During ESS, Keros type III fossa is at a greater risk for skull base injury than type I fossa. ${ }^{5)}$ A few studies have reported a direct relationship between the pneumatization of FS and the LLL. ${ }^{1,2)}$ In contrast, another study has reported that lesser the pneumatization of the FS, greater is the LLL. ${ }^{3)}$ These results could be a matter of contention.

Thus, in this study, we focused on two points. Using computed tomography (CT) multiplanar reconstruction (MPR), first, we investigated the anatomical variants of the PNS and its association with the state of FS pneumatization. Second, we studied the correlation between the degree of pneumatization of the FS, maxillary sinus (MS), and sphenoid sinus (SS) and the LLL.

\section{Subjects and Methods}

\section{Subjects}

We analyzed 966 PNS CT scans that were conducted at our university hospital from July 2017 to December 2018. Patients aged 18 to 70 years were included. Of 802 PNS CT scans, we excluded the patients with surgical history (440 cases), trauma history (28 cases), tumor (16 cases), or an expansile lesion (7 cases). We included total 311 PNS CT scans for the study. After excluding patients with surgical history, trauma history, tumor, or an expansile lesion, 311 PNS CT scans were considered for the study. The approval of the Institutional Review Board of Wonkwang University Hospital was obtained (2020-06-011-001).

\section{Analysis using high resolution sinus tomography}

We analyzed 311 PNS CT scans ( $n=622$, including left and right sides). Tomography was performed using Somatom Definition Flash 256-slice CT scanners (Siemens Healthcare, Forchheim, Germany) with axial plane reconstruction of $1 \mathrm{~mm}$ slice thickness. We classified FS into type I (aplasia), type II (hypoplasia), and type III (control) (Fig. 1). ${ }^{1)}$ In type I, the FS does not pneumatize on the orbital roof at all. Type II shows pneumatization limited to the medial aspect of the midorbital line. FS pneumatization above the orbital roof is defined as type III. Based on the classification by Bolger, et al., ${ }^{6}$ the MS was assigned as control and hypoplasia. Type I hypoplasia is characterized by a normal uncinate process, well-defined infundibular passage, and mild sinus hypoplasia. Type II is characterized by absence or hypoplasia of the uncinate process, an ill-defined infundibular passage, and soft-tissue density opacification of a significantly hypoplastic sinus. Type III shows absence of the uncinate process and a profoundly hypoplastic, cleft-like sinus. In our study, we did not come across type III, and thus classified type I and II as hypoplasia of the MS. The SS was classified into sellar and presellar types.

We investigated superior turbinate pneumatization (STP), middle turbinate pneumatization (MTP), agger nasi cell (ANC), infraorbital cell (IOC), optic nerve (ON) type, and vidian nerve (VN) type. We categorized ON canals into four types using the classification system by Itagi, et al. ${ }^{7)}$ (Fig. 2). Type I canal is superolateral to the SS and does not indent on the sinus wall, as seen on the coronal CT planes. Type II canal is indented on the SS contour and the indented portion is less than $50 \%$ of the nerve circumference. Type III canal traverses through the SS and coronal sections showing more than $50 \%$ projection of ON circumference into the SS. Type IV is a canal adjacent to the SS and posterior ethmoid sinuses/Onodi cell. Con-
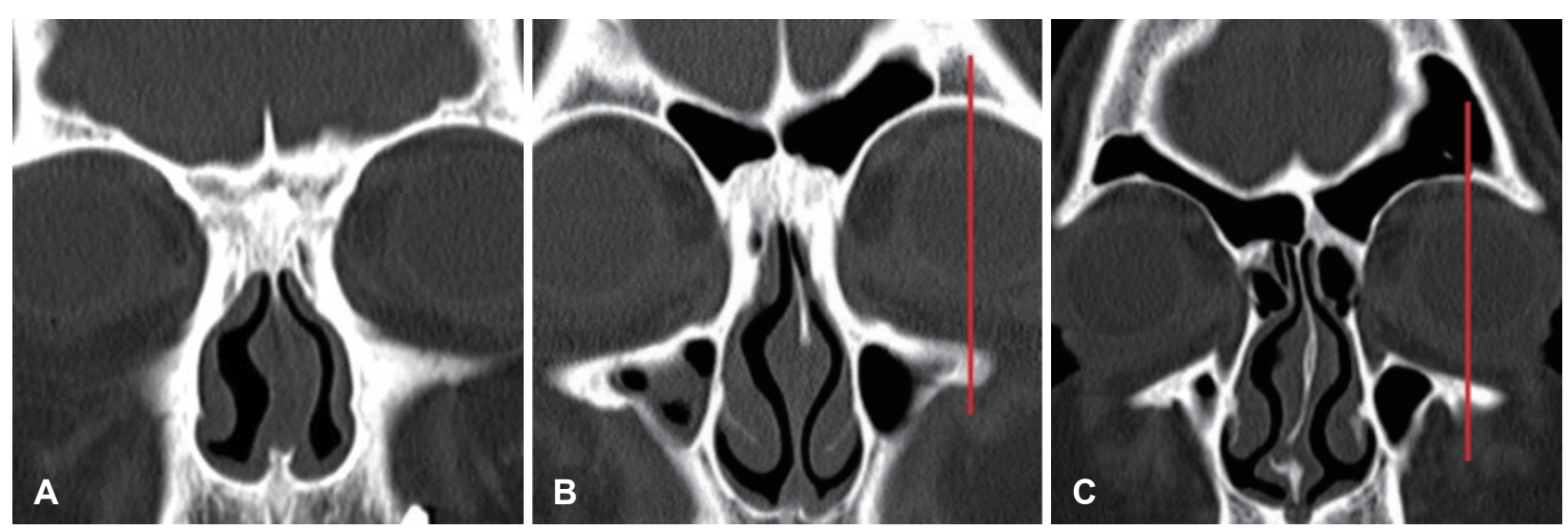

Fig. 1. Classification of frontal sinus into the three types on coronal CT. Type I (aplasia) (A), type II (hypoplasia) (B), type III (control) (C). Red line indicates midpupillary line. 
figurations of the VN were classified into three types (Fig. 3). Type I is considered when the VN canal completely protrudes into the SS; type II, when the canal partially protrudes into the SS or into the floor of the SS; and type III, when the canal is completely obscured within the sphenoid corpus. ${ }^{8)}$

The LLL was measured as the distance between the fovea ethmoidalis and the horizontal cribriform plate in the olfactory fossa, as observed on the coronal plane in which the crista galli was well observed (Fig. 4). ${ }^{3)}$ Two otolaryngologists analyzed each case, and on disagreement, a unified opinion was considered after referring to a third otolaryngologist.
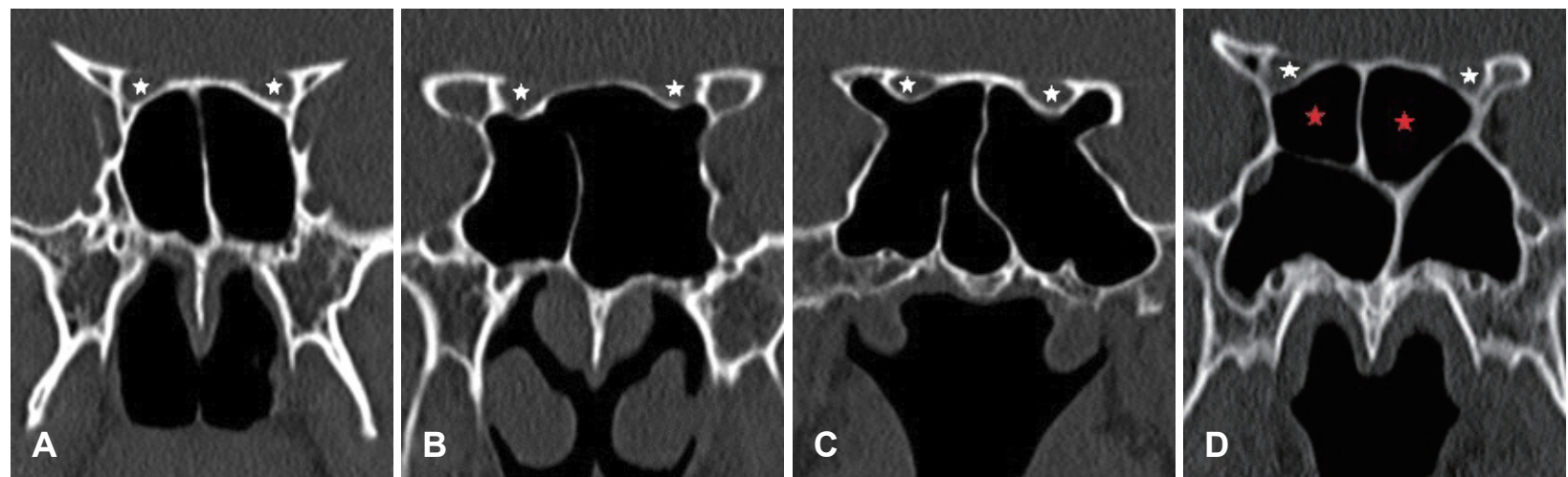

Fig. 2. Classification of ON into the four types on coronal CT. Type I (A), type II (B), type III (C), type IV (D) (white star: ON, red star: Onodi cell). ON: optic nerve.
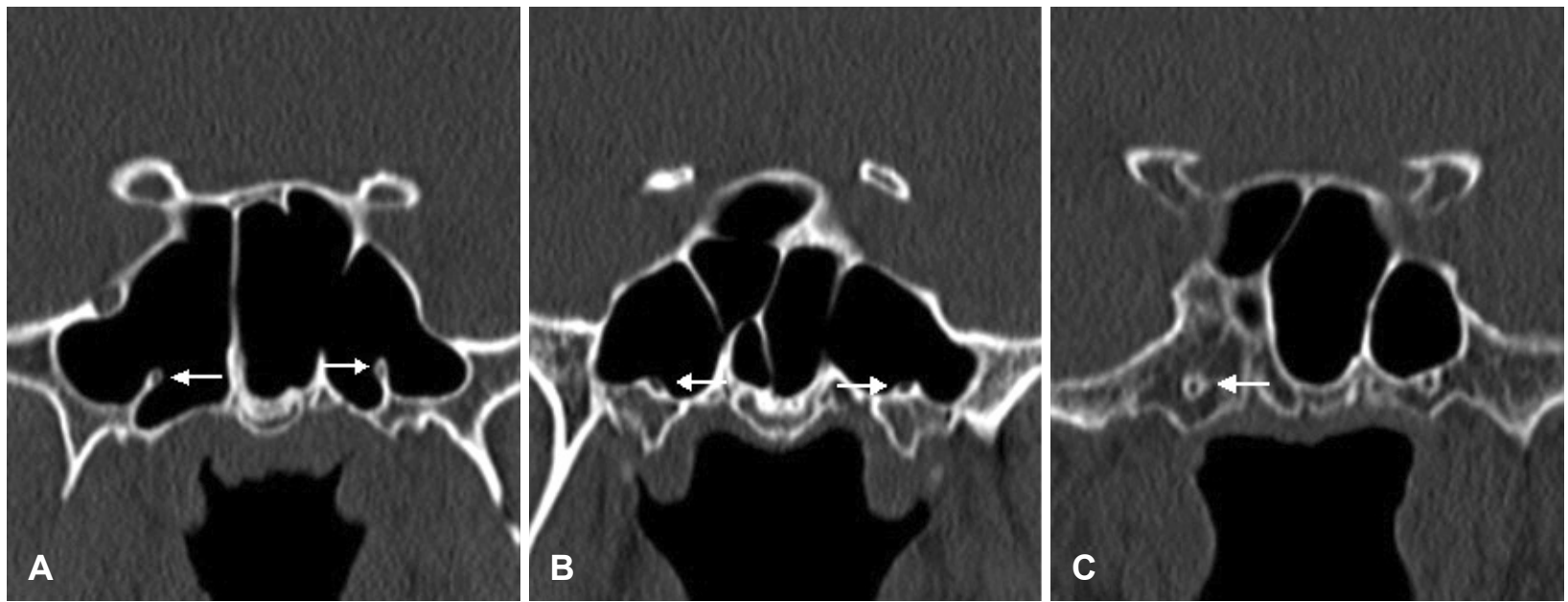

Fig. 3. Classification of vidian nerve (arrow) into the three types on coronal CT. Type I (A), type II (B), type III (C).
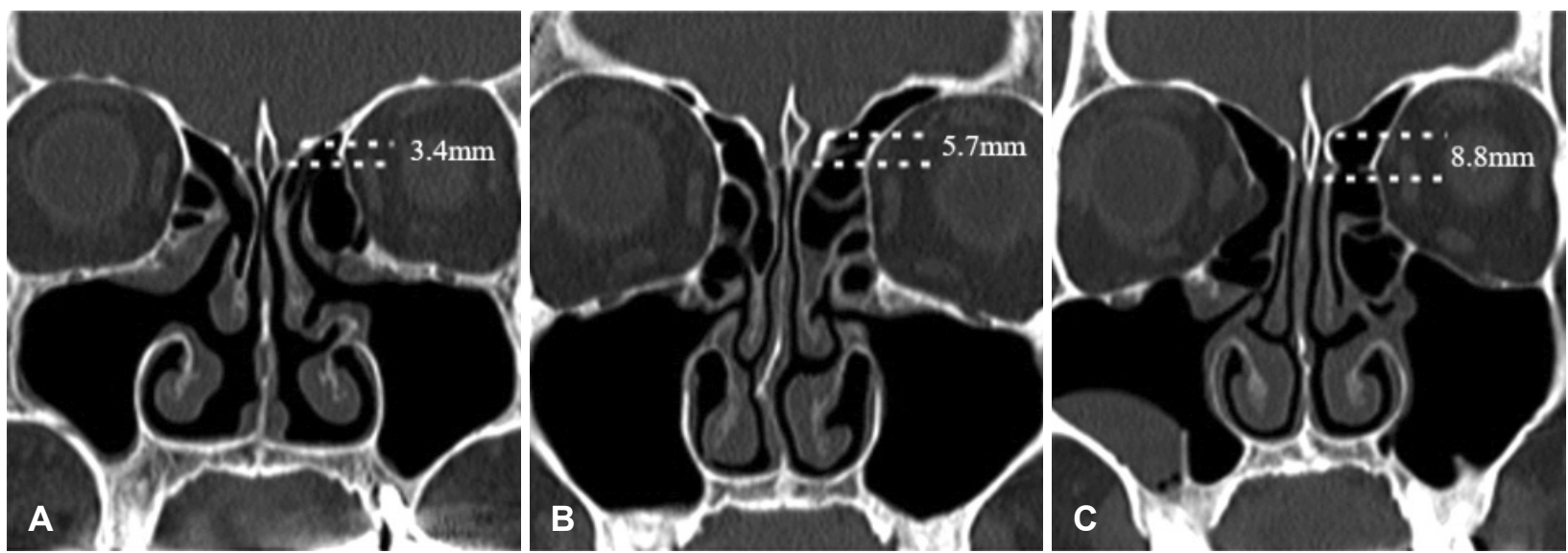

Fig. 4. The lateral lamella length was measured as the distance between the fovea ethmoidalis and the horizontal cribriform plate in the olfactory fossa of the coronal plane of paranasal sinus CT in which the crista galli was exactly well observed (A-C). 


\section{Statistics}

Statistical analyses were performed using IBM SPSS Statistics (version 24) (IBM Corp., Armonk, NY, USA). Chi-square test and Fisher's exact test were applied for the evaluation of anatomical structures and variations of paranasal structures among the three groups of the FS. One-way analysis of variance method was used to compare the LLL among the three groups of the FS. Post-hoc comparisons were conducted using Scheffe's test. Student independent t-test was performed to determine the relation between the LLL and the hypoplastic and control MS and the presellar and sellar types of SS. A $p$ value of $<0.05$ was considered to indicate statistical significance.

\section{Results}

\section{Subjects}

Out of 622 sides that were analyzed, 52 FS were noted as aplasia, 271 as hypoplasia, and 299 as control. The mean age of the patients was $50.88 \pm 14.39$ years. The average ages of the aplasia, hypoplasia, and control groups were $57.06 \pm 9.45$, $52.81 \pm 14.00$, and $48.07 \pm 14.86$ years, respectively. There were 169 men (54.3\%) and 142 women (45.7\%). Among men, FS type I, II, and III were observed in 22, 129, and 187 cases, respectively. In women, FS type I, II, and III were observed in 30, 142, and 112 cases, respectively. We observed more women with FS type I and more men with type III, and there was a significant difference seen between men and women $(p<$ 0.001) (Table 1).

\section{STP, MTP, ANC, and IOC prevalence according to the FS type}

STP was noted with 7, 97, and 107 cases among FS type I, II, and III, respectively. Both, type II and III, showed more frequent occurrences of STP than type I ( $p=0.005)$. In type I, 10 cases showed MTP, while 88 and 102 cases showed MTP in FS type II and III, respectively. There were no significant differences among all the types $(p=0.105)$. All 52 cases of FS type I revealed ANC. In FS type II and III, there were 261 and 292 cases with ANC, respectively, with no significant difference observed ( $p=0.278$ ). IOC was noted in 4,38 , and 48 cases among FS type I, II and III, respectively. There were no significant differences among them $(p=0.276)$ (Table 1).

\section{MS and SS pneumatizations according to the FS type}

In FS type I, II, and III, MS was controlly pneumatized in 44, 236, and 275 cases, respectively. Furthermore, in FS type I, II, and III, MS hypoplasia occurred in 8, 35, and 24 cases, respectively. There were no significant differences observed ( $p=0.091$ ). FS type I, II, and III showed 20, 40, and 30 cases of presellar SS while sellar SS was noted with 32, 231, and 269 cases, respectively. No significant difference was ob-

Table 1. Paranasal sinus variants and sex prevalence according to the FS types

\begin{tabular}{|c|c|c|c|c|c|}
\hline & FS type I & FS type II & FS type III & Total & \\
\hline & n (\%) & $\mathrm{n}(\%)$ & $\mathrm{n}(\%)$ & n (\%) & $\rho$ \\
\hline $\operatorname{Sex}(M / F)$ & $22(42.3) / 30(57.7)$ & $129(47.6) / 142(52.4)$ & $187(62.5) / 112(37.5)$ & $338(54.3) / 284(45.6)$ & $<0.001$ \\
\hline $\operatorname{STP}(-/+)$ & $45(86.5) / 7$ (13.5) & 174 (64.2) / 97 (35.8) & 192 (64.2) / 107 (35.8) & 411 (66.0) / 211 (33.9) & 0.005 \\
\hline MTP $(-/+)$ & $42(80.8) / 10(19.2)$ & $183(67.5) / 88(32.5)$ & $197(65.9) / 102(34.1)$ & $422(67.8) / 200(32.1)$ & 0.105 \\
\hline ANC (-/+) & $0(0.0)$ / 52 (100.0) & $10(3.7) / 261$ (96.3) & 7 (2.3) / 292 (97.7) & $17(2.7)$ / 605 (97.2) & 0.278 \\
\hline $\operatorname{IOC}(-/+)$ & $48(92.3) / 4(7.7)$ & $233(86.0) / 38$ (14.0) & $251(83.9) / 48(16.1)$ & $532(85.5) / 90(14.4)$ & 0.276 \\
\hline MS type (H/C) & $8(15.4) / 44(84.6)$ & $35(12.9)$ / $236(87.1)$ & $24(8.0)$ / 275 (92.0) & 67 (10.7) / 555 (89.2) & 0.091 \\
\hline SS type (P/S) & $20(38.5) / 32(61.5)$ & 40 (14.8) / 231 (85.2) & 30 (10.0) / 269 (90.0) & $90(14.4) / 532$ (85.5) & 0.057 \\
\hline ON type & & & & & $<0.001$ \\
\hline Type I & $32(61.5)$ & $136(50.2)$ & $95(31.8)$ & $263(42.3)$ & \\
\hline Type II & $10(19.2)$ & $72(26.6)$ & $85(28.4)$ & $167(26.8)$ & \\
\hline Type III & $1(1.9)$ & $13(4.8)$ & $38(12.7)$ & $52(8.4)$ & \\
\hline Type IV & 9 (17.3) & $50(18.5)$ & $81(27.1)$ & $140(22.5)$ & \\
\hline VN type & & & & & $<0.001$ \\
\hline Type I & $5(9.6)$ & $54(19.9)$ & $97(32.4)$ & $156(25.0)$ & \\
\hline Type II & $10(19.2)$ & $95(35.1)$ & 119 (39.8) & $224(36.0)$ & \\
\hline Type III & $37(71.2)$ & $122(45.0)$ & $83(27.8)$ & 242 (38.9) & \\
\hline
\end{tabular}

(-): absence, (+): presence, $\mathrm{p}$-value<0.05: significant difference. FS: frontal sinus, $\mathrm{n}$ : number, $\mathrm{M}$ : male, F: female, - : abscent, +: present, STP: superior turbinate pneumatization, MTP: middle turbinate pneumatization, ANC: agger nasi cell, IOC: infraorbital cell, MS: maxillary sinus, H: hypoplasia, C: control, SS: sphenoid sinus, P: presellar, S: sellar, ON: optic nerve, VN: vidian nerve 
served $(p=0.057)$ (Table 1).

\section{ON and VN types according to the FS type}

ON type I, II, III, and IV were present in 32, 10, 1, and 9 cases, respectively, in FS type I cases; 136, 72, 13, and 50 cases, respectively, in FS type II cases; and 95, 85, 38, and 81 cases, respectively, in FS type III cases. The ON type III and IV were significantly frequent in FS type III $(p<0.001)$. In FS type I, there were 5 cases of VN type I, 10 cases of type II, and 37 cases of type III. FS type II cases revealed 54, 95, and 122 cases of VN type I, type II, and type III, respectively. VN type I, II, and III were noted in 97, 119, and 83 cases, respectively, among FS type III. The occurrence of VN type III in FS type I was significant $(p<0.001)$ (Table 1$)$.

\section{Comparison of LLL according to the FS, MS, and SS types}

In FS type II and III, the LLL was significantly greater than in type I $(p<0.001)$ (Table 2$)$. There was no significant difference between FS type II and III ( $p>0.05)$. When comparing the LLL with MS and SS types, there were no significant difference ( $p=0.208, p=0.762$, respectively) (Table 3 ).

\section{Discussion}

In this study, we attempted to confirm our speculation about a possible correlation between the pneumatization of FS and the development of other PNS structures. To the best of our knowledge, there are only few related studies in the literature.

In our study, STP rate was significantly higher in type II and III than I. However, MTP rate according to FS type was not significant. In the study by Yazici, ${ }^{4)}$ STP rate was $12.5 \%$ in FS type I, 30\% in type II, and 50\% in type III, significantly higher in type III. In their study, MTP rate was $44.2 \% ; 30.0 \%$ in FS type I, $40.0 \%$ in type II, and $62.5 \%$ in type III, significantly higher in type III. Unlike our study, Yazici ${ }^{4)}$ showed significant differences in MTP rate; this is probably because their study targeted Turkish and our study Koreans. That is, it may have been caused by racial and geographical differences. The study by Yazici) ${ }^{4}$ showed similar results, indentation rates of ON and VN being higher in the FS type III than in type I or II. The ON types III and IV are more susceptible to damage during ESS.

Greater LLL has a significant clinical implication. The lateral lamella of the cribriform plate is the thinnest part of the skull base, known as the common injury area during ESS.9) The thickness of the lateral lamella is known to be only 0.05 $\mathrm{mm}$. Greater tendency of damage is suspected with an increase in the length of lateral lamella; hence, great caution is suggested during the operation.

In our study, the mean LLL of type II and III were significantly greater than that of type I but the MS and SS types and the LLL were not significantly correlated. Kayabasi, et al. ${ }^{3)}$ observed that the pneumatization defects of MS, FS, and SS were related to deeper olfactory fossa and longer lateral lamella. In their study, the mean LLL of the FS aplasia group was $6.53 \pm 1.78 \mathrm{~mm}, 5.98 \pm 1.94 \mathrm{~mm}$ in the FS hypoplasia group, and $4.28 \pm 1.52 \mathrm{~mm}$ in the control FS group $(p<0.001)$. They found that patients with MS and SS hypoplasia had a deeper olfactory fossa and longer lateral lamella. However, a few studies showed similar results to ours. ${ }^{1,2)}$ Çomoğlu, et al. ${ }^{1)}$ reported deeper olfactory fossa in extensively pneumatized FS cases, with a mean LLL of $4.17 \pm 1.44 \mathrm{~mm}$ in FS type I, $5.15 \pm$ $1.50 \mathrm{~mm}$ in type II, and $5.60 \pm 1.41 \mathrm{~mm}$ in type III. Kayabasi, et al. ${ }^{3)}$ and two other studies ${ }^{1,2)}$ surveyed the Turkish people and obtained different results.

The limitation of this study is its small number of FS type I compared to type II and III, which is a very small representation of the general population. The development of the FS may differ depending on gender, race, and region. Bilateral FS aplasia was reported to vary from 1.3 to $43.0 \%$ in previous studies. In a Korean study by Sim, et al., ${ }^{10)}$ bilateral FS apla-

Table 2. Lateral lamella length according to FS types

\begin{tabular}{|c|c|c|c|c|}
\hline & FS type I & FS type II & FS type III & $p$ \\
\hline Mean LLL (mm) & $4.11 \pm 1.27^{*}$ & $5.52 \pm 1.82^{+}$ & $5.93 \pm 1.8^{\dagger}$ & $<0.001$ \\
\hline
\end{tabular}

Table 3. Lateral lamella length according to maxillary and SS types

\begin{tabular}{lcccccc}
\hline & MS hypoplasia & MS control & $p$ & SS presellar & SS sellar & $p$ \\
\hline Mean LLL $(\mathrm{mm})$ & $5.88 \pm 1.91$ & $5.57 \pm 1.87$ & 0.208 & $5.55 \pm 2.00$ & $5.62 \pm 1.86$ & 0.762 \\
\hline p-value $<0.05$ : significant difference. LLL: lateral lamella length, MS: maxillary sinus, SS: sphenoid sinus & &
\end{tabular}


sia was observed in $2.9 \%$ of men and $7.1 \%$ of women. Unilateral FS aplasia has been reported to vary from 0.8 to $14.3 \%$ in different studies. Sim, et al. ${ }^{10)}$ reported an incidence of 5.4 and $5.3 \%$ in men and women, respectively. This relatively low rate of FS aplasia is consistent with our results. We studied limited CT scans that were conducted from July 2017 to December 2018, thus accounting to a small sample size. A larger number of PNS CT scans need to be analyzed for further studies.

In conclusion, this study correlated the variations of PNS structures to the FS development and compared the LLL according to the FS, SS, and MS pneumatization. In our study we observed greater indentation of the $\mathrm{ON}$ and $\mathrm{VN}$ into the SS and a longer LL with increasing FS pneumatization. Therefore, surgeons should be more cautious and carefully review the CT scan to avoid damage of the important structures such as the LLL, ON, and VN, in cases of well pneumatized FS.

\section{Acknowledgments}

None.

\section{Author Contribution}

Conceptualization: Myeongsin Kang, Jae-Hoon Lee. Data curation: all authors. Formal analysis: Myeongsin Kang, Jae-Hoon Lee. Investigation: all authors. Methodology: all authors. Supervision: Jae-Hoon Lee. Writing — original draft: Myeongsin Kang, Jae-Hoon Lee. Writing — review \& editing: Jae-Hoon Lee.

\section{ORCID}

Jae Hoon Lee

https://orcid.org/0000-0002-0856-8173

\section{REFERENCES}

1) Çomoğlu Ş, Şahin B, Sönmez S, Değer K. Frontal sinus pneumatization affects height of the lateral lamella and position of anterior ethmoidal artery. J Craniofac Surg 2017;28(1):265-9.

2) Gumus C, Yildirim A. Radiological correlation between pneumatization of frontal sinus and height of fovea ethmoidalis. Am J Rhinol 2007;21(5):626-8.

3) Kayabasi S, Hizli O, Ozkan D. Does paranasal sinus development affect olfactory fossa depth and lateral lamella length? Laryngoscope 2019;129(11):2458-63.

4) Yazici $D$. The effect of frontal sinus pneumatization on anatomic variants of paranasal sinuses. Eur Arch Otorhinolaryngol 2019; 276(4):1049-56.

5) Güldner C, Diogo I, Windfuhr J, Bien S, Teymoortash A, Werner JA, et al. Analysis of the fossa olfactoria using cone beam tomography (CBT). Acta Otolaryngol 2011;131(1):72-8

6) Bolger WE, Woodruff WW Jr, Morehead J, Parsons DS. Maxillary sinus hypoplasia: Classification and description of associated uncinate process hypoplasia. Otolaryngol Head Neck Surg 1990;103(5 (Pt 1)): 759-65.

7) Itagi RM, Adiga CP, Kalenahalli K, Goolahally L, Gyanchandani $M$. Optic nerve canal relation to posterior paranasal sinuses in Indian ethnics: Review and objective classification. J Clin Diagn Res 2017;11(4):TC01-03.

8) Lee JC, $\mathrm{Kao} \mathrm{CH}$, Hsu CH, Lin YS. Endoscopic transsphenoidal vidian neurectomy. Eur Arch Otorhinolaryngol 2011;268(6):851-6.

9) Gera R, Mozzanica F, Karligkiotis A, Preti A, Bandi F, Gallo S, et al. Lateral lamella of the cribriform plate, a keystone landmark: Proposal for a novel classification system. Rhinology 2018;56(1): 65-72.

10) Sim YC, Kang M, Yu JS, Lee JH. Pneumatization of the frontal and sphenoid sinus in Korean adults: A study of using computed tomography scans. Korean J Otorhinolaryngol-Head Neck Surg 2018;61(7):349-54. 